\title{
Four facets of learning in performance measurement
}

J ason Martin, Mattias Elg, Andreas Wallo and Henrik Kock

The self-archived postprint version of this journal article is available at Linköping University Institutional Repository (DiVA):

http:// urn.kb.se/ resolve?urn=urn:nbn:se:liu:diva-152037

N.B.: When citing this work, cite the original publication.

Martin, J ., Elg, M., Wallo, A., Kock, H., (), Four facets of learning in performance measurement, International J ournal of Productivity and Performance Management.

https:// doi.org/ 10.1108/ IJ PPM-11-2017-0320

Original publication available at:

https:// doi.org/ 10.1108/IJ PPM-11-2017-0320

Copyright: Emerald

http:// www.emeraldinsight.com/ 


\title{
Four facets of learning in performance measurement
}

\begin{abstract}
Purpose - The purpose of this study is to contribute to a better understanding of the role of learning in performance measurement.

Design/methodology/approach - We develop a theoretical framework combining workplace learning theory with purposes of performance measurement. We elaborate this framework empirically by identifying critical incidents from a case set within a context containing a broad range of different performance measurement activities. Finally, we discuss the results and the possible implications for using our theoretical framework in order to better understand facets of learning regarding the design of performance measurement.
\end{abstract}

Findings - Workplace learning theory provides a deeper understanding of how the mechanisms of performance measurements support control or improvement purposes. We propose a tentative framework for learning as a driver for performance measurement and four facets of learning are identified: reproductive, rule-oriented, goal-oriented and creative learning.

Research limitations/implications - The empirical material is limited to the healthcare context and further studies are needed in order to validate the findings in other settings.

Practical implications - We argue that all managers must consider what kind of learning environment and what kind of learning outcomes best serve the interests of their organisation. Purposeful and carefully designed organisational arrangements and learning environments are more likely to induce intended learning outcomes.

Originality/value -Previous connections between the fields of 'performance measurement' and 'workplace learning' often lack any deeper conceptualisations or problematisations of the concept of learning. In this paper, we provide a more nuanced discussion about the process of learning in performance measurement, which may provide a basis for further research and scholarly attention.

Keywords: Performance measurement, workplace learning, control, improvement, adaptive learning, developmental learning. 


\section{Introduction}

A number of challenges caused by globalisation, digitalisation and the changing nature of work have influenced how most organisations operate and improve their performance. There is widespread agreement that performance measurement is one way to handle these challenges, and is therefore a core element of modern management in any business (Bititci et al., 2012; Neely, 1999; Pollitt, 2013). This broad interest emanates from the central management problem of increasing efficiency as well as effectiveness (Neely et al., 2005).

The versatility and ability to use performance measurement for different purposes is striking. It plays a key role in developing strategic plans, prioritising strategies, evaluating achievements of objectives and setting the stage for organisational improvements. An important feature of performance measurement, cutting across any context or purpose of use, is its potential to create different conditions for learning within organisations (cf. Bohmer, 2009; Chenhall, 2005; Lucas, 2015; Wang, 2018). The notion of learning in the context of performance measurement has been proposed in relation to a broad range of topics, such as manager development (cf. Appuhami, in press; Lebas, 1995; Sun and Henderson, 2016), as a means for employees to understand their business (cf. Nudurupati et al., 2011; Taylor and Taylor, 2014), stimulation of problem-solving (Mausolff, 2004), and critical reflection on strategy (cf. Santos-Vijande, López-Sánchez and Trespalacios, 2012; Neely and Al Najjar, 2006). Although there is consensus about the importance of learning in performance measurement (cf. Aranda et al., 2017; Franco-Santos, Lucianetti and Bourne, 2012; Melnyk et al., 2014), a shift towards an increased focus on learning can be seen as a key challenge for actual performance measurement practices (cf. Aragon et al., 2014; Bititci et al., 2012).

There are numerous examples of theoretical frameworks encompassing both learning and performance measurement (cf. Aragon et al., 2014; Brudan, 2010; Zhou, Hu and Shi, 2015). Although these studies provide valuable insights, they do not further problematise and elaborate on the concept of learning (cf. Santos-Vijande, López-Sánchez and Trespalacios, 2012; Fang, Li and Lu, 2016). Empirical, qualitative studies extending a deeper understanding on learning processes in relation to performance measurement practices are scarce. By drawing on theories from workplace learning (cf. Argyris and Schön, 1978; Billet, 2001; Engeström, 1987; Ellström, 2011; Tynjälä, 2013), we want to explore the diverse and complex ways in which learning is embedded in performance measurement practices. The complexity of learning is manifested in its duality as constituting both a process and an outcome. Therefore, it could be claimed that the content of performance measurement is defined by learning and vice versa.

The purpose of this study is to understand this duality and explore the role of learning in performance measurement. We aim to develop a framework in which two main contrasting purposes of performance measurement - control and improvement - are connected to four different facets of learning processes in organisations: reproductive, rule-oriented, goal-oriented and creative learning. A key issue is to understand what characterises learning in situations when performance measurement facilitates control (that is, where there is a need for efficient, routinised work); and what characterises learning when performance measurement drives creative and developmental actions.

We extend our investigation in four main steps. First, we present previous research and a theoretical framework. Second, we propose a tentative framework for learning processes in performance measurement. Third, we present data from a case study set within a performance measurement rich health-care context. In the final step, we discuss the framework and present implications in using performance measurement for learning in organisations. 


\section{Previous research}

A recurring theme within performance measurement literature is to define and understand the different purposes and roles of performance measurement in organisations (cf. Bond, 1999; Elg, 2007; Neely, 1999; Franco-Santos et al., 2007; Pidd, 2012; Serrat, 2017). Behn (2003) described eight main purposes of performance measurement: evaluate, control, budget, motivate, promote, celebrate, learn and improve. Although the studied literature offers an array of different performance measurement purposes, two overarching and governing "meta-purposes" that can be readily identified and control and improvement. A central problem in the use of performance measurement is that it 'just keeps the score' (Bourne, 2008, p. 68), instead of facilitating change. Therefore, we stress a need to explore learning purposes and improvement in performance measurement practice.

Early examples of literature incorporating learning and performance measurement often adopt a strategic and systems-oriented perspective (cf. Bourne et al., 2002; Dervitsiotis, 2004; Neely, Gregory and Platts, 2005; Neely, 1999; Chenhall, 2005; Franco-Santos et al., 2007). Recent studies have continued the strategic and systemsoriented approach (cf. Appuhami, in press; Fang, Li and Lu, 2016; Zhou, Hu and Shi, 2015). Some studies have challenged the traditional control perspective on the use of measurements and offered an alternative view on performance measurement systems as 'a means of challenging assumptions' (Neely and Al Najjar, 2006, p.102) and also as a learning tool (Canonico et al., 2015; Dossi and Patelli, 2010).

Most studies on learning and performance measurement are quantitative, with few qualitative or conceptual studies more elaborately integrating the processes and practices of learning and performance measurement. Learning is often addressed only briefly and most studies lack an deeper understanding and analysis of how learning theory and learning processes affect performance measurement and vice versa. Also, several studies have adopted a somewhat instrumental view, presuming a causal chain with learning supporting or facilitating the use of performance measurement systems and rarely, if at all, the other way around (cf. Aragon et al., 2014; Fink et al., 2017; Hussain et al., 2016). Few empirical studies have described the particular learning process or elaborated how learning processes and performance measurement practices interact. Even fewer have extended a deeper understanding of what actually constitutes learning in performance measurement systems, or indeed the very nature of the particular learning processes contained therein. According to Behn (2003), learning and performance measurement are about determining what is working, or not working, and then figuring out how to make improvements based on these new insights. The present study is an attempt to increase knowledge about the relation between 'determining what is working, or not' and the nature and quality of the 'figuring out'.

Based on the examined literature, two main conclusions can be discerned. First, the often piecemeal handling of the concept of learning, in relation to performance measurement, implies that learning is perceived as something of a 'black box' that is often left without any further problematisation or extended discussion. Questions about what is learnt and by whom are rarely addressed and previous research has made few attempts to distinguish between different meanings of the concept. Secondly, there appears to be a gap in the performance measurement literature on the needs of managers to better understand learning processes in order to utilise performance measurement to its full potential. We argue that managers need to have an equal understanding of both performance measurement and learning processes in order to optimise them both in successful organisations. 


\section{Theoretical framework}

To open up the 'black box' of learning, we will employ a workplace learning perspective (Billet, 2001; Engeström and Kerosuo, 2007; Ellström, 2011; Tynjälä; 2013) to discuss learning in relation to performance measurement. The field of workplace learning research has grown extensively and a large number of interdisciplinary studies have been carried out in this area (Manuti et al., 2015). Rapid economic, social and cultural changes have led organisations to realise the importance of issues concerning workplace learning and employee development (Tynjälä, 2013). Therefore, the workplace is no longer only seen as a site for production, but also as an environment for facilitating learning (Ellström, 2001).

From a workplace learning perspective, learning implies both formal training activities (such as courses) and informal learning. The latter refers to learning as a continuous activity that is inherently integrated into all work activities (Zuboff, 1988). Theoretically, this distinction between formal and informal learning is parallel to Sfard's (1998) notion of learning as acquisition and learning as participation. As learning is truly at the heart of any productive activity (Zuboff, 1988) and productive activity incorporates performance measurement, learning and performance measurement appear to be truly inseparable. Thus, it could be argued that learning forms a point of departure for just about any notion of performance measurement and is not, as Behn (2003) stated, a separate end exclusive performance measurement purpose. Therefore, learning can be said to be not just an outcome but perhaps also be a prerequisite for an activity, or a part of the activity itself (Antonacopoulou, 2006; Tynjälä, 2013).

There are several similar ways of conceptualising different types of learning. Argyris and Schön (1978) elaborated the influential concepts of single-loop and double-loop learning. Engeström (1987) developed expansive and restrictive learning, and March (1991) proposed a difference between exploration and exploitation in organisational learning. In this article, we draw mainly on Ellström's (2010) distinction between adaptive and developmental learning, which builds on, and to some extent also elaborates, these previous conceptualisations of learning in the workplace.

Adaptive learning is obtained through routine action, where rules and instructions are followed for known problems or situations. This type of learning is primarily instrumental and is valued when it promotes effective action, leading to a learning environment that is characterised by security, standardisation, exploitation and consensus. Thus, adaptive learning happens on a more routine basis, often aiming to improve something that has already been mastered. Developmental learning, by contrast, is characterised by reflective and alternative thinking, risk-taking, critical reflection and the desire to experiment (Ellström, 2010; 2011). Uncertainty and divergence are seen as potential generators of exploration rather than as threats or inconveniences. According to Ellström (2011), these two learning types should be perceived as complementary.

The question of whether learning is adaptive or developmental requires a discussion on the conditions in the workplace that may enable or constrain learning; that is, the learning environment (Coetzer, 2007; Fuller and Unwin, 2004; Kock and Ellström, 2011). This learning environment comprises conditions provided by an employer, such as the learning potential of the work tasks, the work organisation, and the available learning resources. Subjective factors that also seem to affect the individual's engagement in learning activities include self-confidence, motivation, values, previous learning experiences and learning readiness (Billet, 2001). Engaging in a learning process is not automatic (Tidd, 1997) and there may also be specific problems that affect engagement in learning activities. In their study on learning, learning networks and shared learning in organisations, Bessant and Tsekouras (2001) listed seven main learning blocking factors 
together with their underlying problems: lack of entry to learning cycle, incomplete learning cycle, weak links in the learning cycle, lack of learning skills or structure, knowledge remains in tacit form, repeated learning (without capturing or codifying the learning content), and infrequent, sporadic and unsustained learning.

When it comes to learning in performance measurement, it is particularly interesting to explore the learning potential of the task, and especially the discretion that the task entails. Discretion refers to the degrees of freedom, or scope of action, that the learning subject has regarding how the task is defined, how the methods for solving the task are chosen and how the results should be evaluated (Ellström, 2001). Hackman (1969) listed understanding, acceptance, idiosyncratic needs and values, as well as previous experience with similar tasks, as factors that affect the motivation, performance and outcome (or results) of tasks. In combining these factors - task, method and results - Ellström distinguished four levels, or as we prefer to label them, facets of learning (see Table I).

Table I. A taxonomy of facets of learning as a function of the discretion that exists in the learning environment (adapted from Ellström, 2001, p. 423).

\begin{tabular}{lccccc}
\hline & \multicolumn{3}{c}{ Facets of learning } \\
\hline \multirow{2}{*}{$\begin{array}{l}\text { Aspects of the } \\
\text { learning situation }\end{array}$} & $\begin{array}{c}\text { Adaptive learning } \\
\text { Reproductive }\end{array}$ & $\begin{array}{l}\text { Productive type I } \\
\text { (rule-oriented) }\end{array}$ & & $\begin{array}{l}\text { } \\
\text { Productive type II } \\
\text { (goal-oriented) }\end{array}$ & Creative \\
Tasks & Given & Given & & Given & (3) \\
Methods & Given & Given & & Not given & Not given \\
Results & Given & Not given & & Not given & Not given \\
\hline
\end{tabular}

By using facets rather than levels, we embrace the notion that learning is not a hierarchical phenomenon in which 'higher-level' learning processes presuppose superiority over 'lower-level' learning processes. We adopt the view that different contexts and settings induce different learning processes, sometimes even simultaneously.

In Table I, reproductive learning (1) represents a facet of learning that occurs when the tasks, methods and results are predetermined. This facet of learning is sufficient and necessary for many activities, but its primary function is in the formation of competencies for automatically solving routine assignments. Reproductive learning primarily supports the accumulation of tacit knowledge (Polyani, 1967) within individuals. An example of reproductive learning situations could be the use of routinised day-to-day measurements serving a documented purpose used to adapt or refine existing routines. The next facet of learning is called productive learning and it comes in two slightly different types: ruleoriented (2) and goal-oriented (3). Rule-based productive learning is characterised by a higher degree of discretion when it comes to the evaluation of results. The learning subject must evaluate the outcomes and make minor changes to the methods used to solve the task. One example of rule-oriented learning is the use of routinised day-to-day measurements that serve a documented purpose but are used to develop new ways of working. As well as having a higher degree of discretion regarding results, goal-oriented productive learning has a higher degree of choice and use of methods. So, even though the task may be given, the learning subject can experiment with ways of solving the problem at hand. One example of goal-oriented learning is adhering to documented and previously designed purposes but allowing for new approaches in the design of measurements and utilisation of results.

In the last facet, creative learning (4), the learner must use his or her own authority not only to evaluate results or chose methods, but also to define the task itself; that is, to 
diagnose the situation. In this facet of learning, the learner is free to question the definitions of tasks and problems posed by the environment (such as colleagues or management) and to act to transform standardised or institutionalised solutions. An example of creative learning could be an environment in which individuals or groups of individuals within an organisation are entrusted to freely reflect on and question established ideologies, devise own measurements, and develop new routines, structures and practices.

\section{Towards a tentative framework for performance measurement as a driver for learning}

Based on our theoretical perspective on learning, we propose a tentative framework as a first attempt to build a theory of various forms of learning in contexts of performance measurement (see Figure 1). The elements of the proposed framework are based on four components: the purpose of performance measurement, the learning type, the learning facets, and the level of agent discretion. The framework is intended to be used in associating learning with performance measurement.

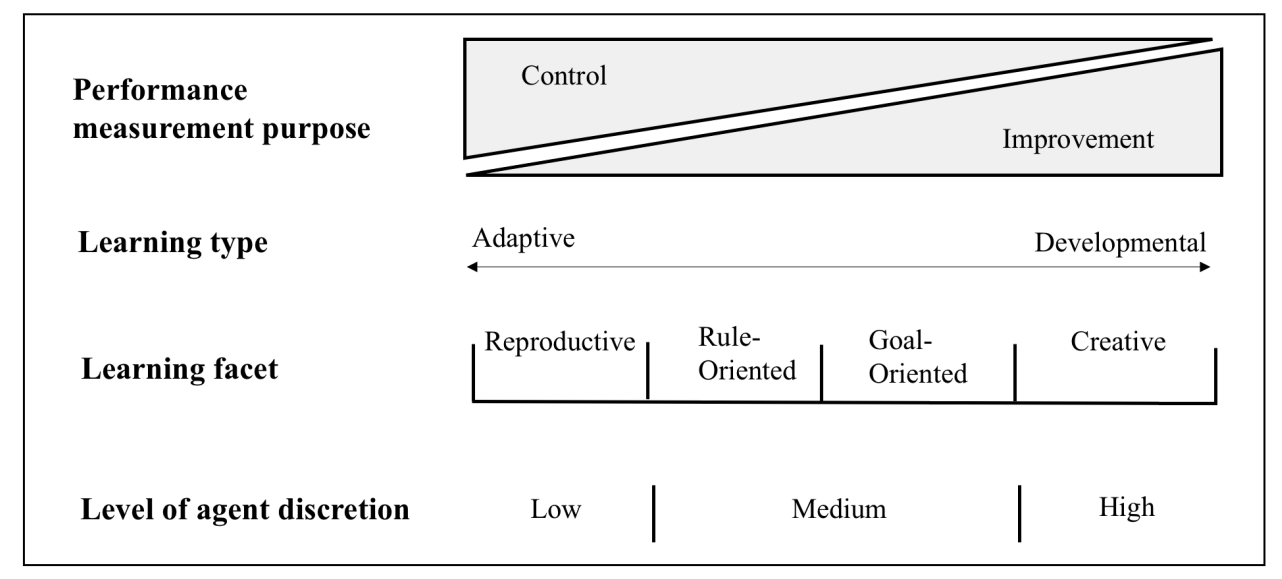

Figure 1. The relation between performance measurement and learning: a proposed framework.

The purpose of performance measurement plays a fundamental role in management. A key assumption in performance measurement is that organisational activities are best controlled and improved through a carefully set of measures that drives performance (Melnyk et al., 2014). Efficient and effective operations management rely on this mechanism (Neely, Gregory and Platts, 2005). However, purposes of performance measurement are rarely clear-cut and rarely serve purely either control or improvement purposes. Therefore, with our framework, we suggest that measurement for control and measurements for improvement can include both learning types and the different learning facets as described below.

The second component is learning type (Ellström, 2010; 2011). Within adaptive learning type contexts, learning from performance measurement is primarily valued if it can contribute to operational efficiency. There is a strong imperative for reliability and learning is strongly connected to the task of reducing variation in operations (Ashton, 2004; Ellström, 2011). With a predominantly adaptive learning type, learning from performance measurement can be said to focus on eliminating errors and aiming for organisational compliance with operational routines and rules. Within adaptive learning, the context and culture supports learning conditions aimed at enhancing and making current operations more efficient (Ellström, 2001; Barley and Kunda, 2001). By contrast, within developmental learning type contexts, the context supports exploration of variation. Any deviation or divergence from routine is viewed as an opportunity for 
knowledge development and as an incentive for incremental improvements and, in some cases, even radical improvement. In such situations, failures are accepted and a certain level of risk-taking is encouraged. The most critical component in a developmental context is organisational acceptance and encouragement for critical thinking and critical reflection (Argyris and Schön, 1978; Ellström, 2001; March and Olsen, 1976).

The third component in the framework consists of the four learning facets (Ellström, 2001). The continuum of reproductive, rule-oriented, goal-oriented, and creative learning is situated along the same axis as the adaptive and development learning type axis. Thus, contexts within a predominantly adaptive learning type would support reproductive and rule-oriented learning to a higher degree, while contexts within a predominantly developmental learning type would be better suited to support goal-oriented and possibly also creative learning.

The fourth and final component in the framework - the level of agent discretion in relation to tasks, methods and results (Ellström, 2001) - is outlined vis-à-vis the other components. As used here, 'agent' is an intentionally acting subject or collective that occupies a structural position (Danermark et al., 2002). Agent discretion, in the form of bounded conditions for participation in operational and organisational development, has been widely addressed in the literature (cf. Ellström, 2001; March and Olsen, 1976; Norros, 1995). Discretion not only requires the individual agent to be able and willing to participate but also to have the right to do so, in the form of organisational acceptance and encouragement (Kock, 2007). Agent discretion will differ for the agents involved in performance measurement activities. In more adaptive learning type contexts, the level of discretion can be characterised as low to medium, and more developmental learning type contexts as medium to high.

Tasks refer to directives or demands that express needs, desired outcomes and intended purposes of the performance measurement (cf. Ellström, 2001; Hackman, 1969). Examples include targets, rules, regulations, orders, professional needs and/or insights. Methods specify the performance measurement methods or practices to be utilised. These can be routine-based, 'one-off' designs and/or experimentally developed. Results are performance measurement outputs that can be specified with clear intentions, or developed according to unforeseen contingencies or arising needs.

\section{Research method}

The data reported in this article were collected in a research project based on case study methodology (Eisenhardt, 1989; Voss, Tsikriktsis and Frohlich, 2002). Our case was an orthopaedic and rheumatologic department located in southeast Sweden, a context in which performance measurement is widely used. The department has about 150 employees in nine sections, treating both planned and acute patients. Each year, approximately 30,000 patients visit the department and approximately 3000 surgeries are performed. The department is considered to be best in class when it comes to utilisation of performance measurement in both production and developmental work.

In line with Voss, Tsikriktsis and Frohlich (2002), the starting point of the present work is that it is necessary to have a rich amount of primary data in order to make sense of the key dimensions and the types of environments that frame learning in performance measurement. We consider this case as instrumental (Stake, 1995). Thus, we are not primarily interested in its intrinsic qualities, but rather in how it enables us to understand and develop our theoretical ideas through analytical generalisation (Firestone, 1993). In previous studies, we have reported the studied organisation's wide variety of activities linked to performance measurement (reference anonymised for blind review). These include higher management's strategic initiatives, strategic goal deployment, continuous 
follow-up in management meetings, improvement work and individual initiatives for decision making. By and large, this provides us with a single case with great potential for studying many variations in which learning may be linked to performance measurement. Thus, we use the case for theory building in the sense that the case supports our work in establishing links between various forms of learning and performance measurement (Voss et al., 2002).

When conducting empirical field work, one of the central problems is grasping realworld activities. This is especially difficult in situations where primary data is collected through interviews. Silverman (2004) argued that it is important for the researcher to acknowledge that leading actors in a studied organisation are interested in representing themselves as goal-oriented, trustworthy, change-oriented and rational. This needs to be taken into account when studying performance measurement. Therefore, general statements by top leaders are of limited value, especially if an organisation is best-inclass. One strategy that we used to deal with this is to collect information from a large range of respondents in the organisations (Alvesson and Sköldberg, 2009). Another strategy is to allow the respondents to recall specific situations from which the dialogue can evolve. This was done through Critical Incident Technique (Flanagan, 1954), which helped us identify critical events related to the application of performance measurement among interviewees. In the interviews, respondents were asked to elaborate on incidents with respect to (1) what was going on in this situation; (2) the types of performance measurements being used; (3) who was involved; and (4) short-term results and the perceived long-term effects. All interviews were recorded and transcribed. A total of 73 critical incidents (CIs) were extracted from the empirical material. The CIs were first reported in a previous study (reference anonymised for blind review).

As discussed above, the respondents for the study were selected in order to maintain a high degree of variation in CIs. The following respondent groups within the orthopaedic unit were included: medical doctors (MD) $(n=3)$, nurses $(n=3)$, assistant nurses $(n=2)$, care unit managers $(n=2$, also with background as nurses), financial manager $(n=1)$, administrative unit manager $(\mathrm{n}=1)$, administrators $(\mathrm{n}=2)$, the clinical department manager $(\mathrm{n}=1$, also MD), organisational developer $(\mathrm{n}=1$, physiotherapist), and physiotherapist $(\mathrm{n}=1)$. In total, 17 respondents were interviewed.

We viewed each critical incident as a specific type of situation (that is, learning environment) that creates various conditions for learning in performance measurement. The analytical procedure followed a structured approach in which our theoretically proposed framework guided the coding of each incident. This helped us validate and make further refinements of our key dimensions and definition of types of learning environments that determined facets of learning.

\section{Results}

Critical Incidents

The analysis of the total number of critical incidents $(n=73)$ revealed 55 incidents in which learning environments could be adequately categorised. Table II lists the four facets of learning, each accompanied by two representative critical incidents describing the particular learning environment. The analysis of each CI concerning discretion (the CI nature of task, methods and results) is outlined briefly. We have also extracted a selection of quotes from the data in order to further illustrate how the particular facet of learning is related to the specific performance measurement. 
Table II. Illustration of typical critical incidents.

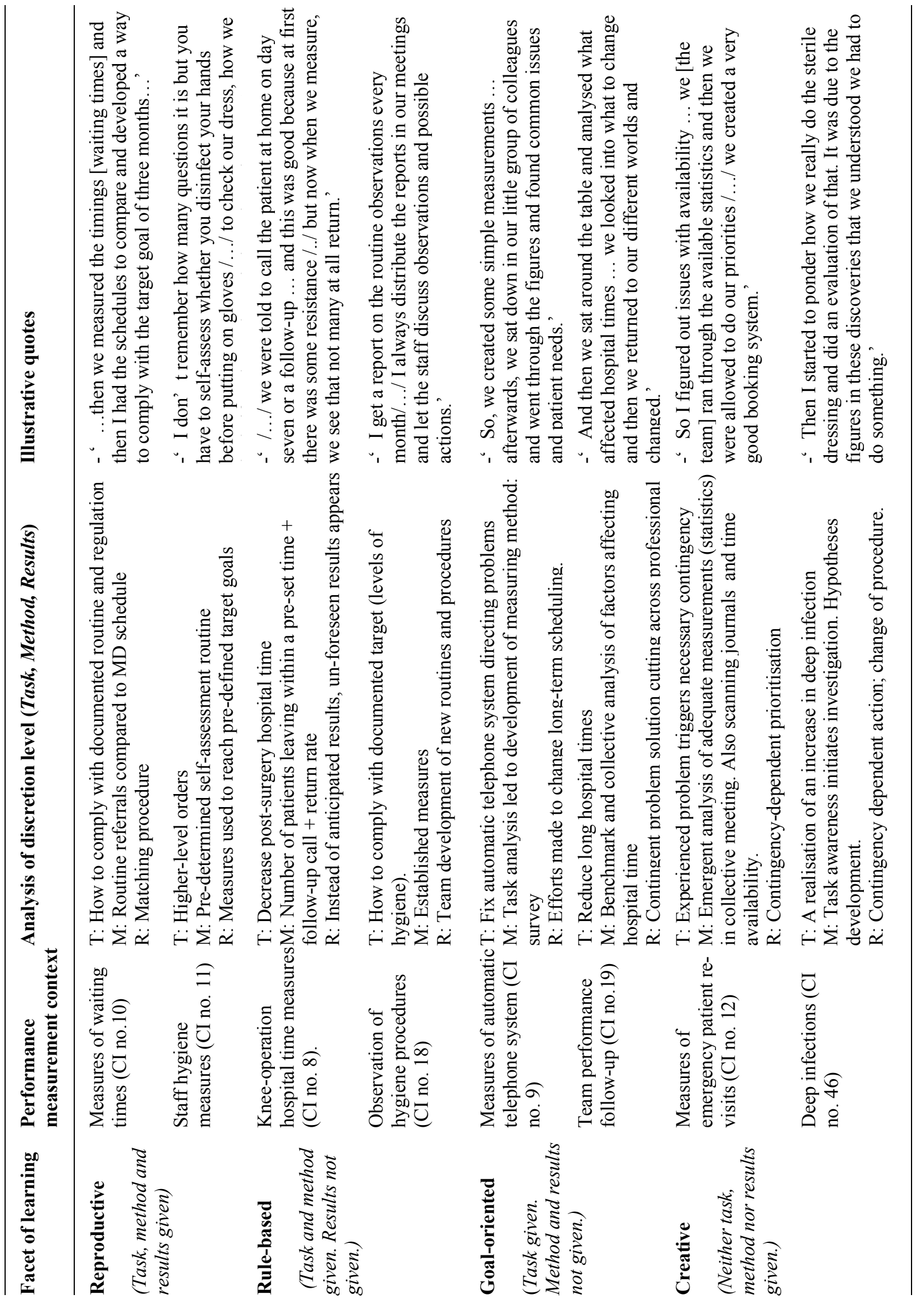


Fifty-five of the 73 CIs comprising the empirical material could be plotted in the framework. These 55 CIs could further be elaborated and categorised in accordance with the particular learning facets each of the supported CIs. Ten CIs (18.2 per cent of the total) could be categorised as performance measurement supporting creative learning. Eight CIs (14.5 per cent) were categorised as performance measurement supporting goaloriented learning. Seventeen CIs (30.9 per cent) were categorised as performance measurements supporting rule-oriented learning and 20 (36.4 per cent) as supporting reproductive learning.

\section{Reproductive learning}

The facet of reproductive learning is reflected in the prescribed nature of the tasks, methods and results within the performance measurement context. The CIs reveal examples with tasks specified according to routines and/or management directives (for example, CIs no. 10 and 11). Performance measurement is initiated as an organisational management action in order to follow standards and regulations, which are either locally or centrally governed. The methods are managed, designed and implemented on a topdown basis and the desired results are set, often in accordance with the task. The staff have little, if any, influence or choice regarding what, how and when the performance measurements should be used.

\section{Rule-oriented learning}

For rule-oriented learning, the CI's reveal a higher agent discretion level concerning results and outcomes. The effects and outcomes of performance measurements are not specified or defined in any detailed sense. CI examples reveal dynamic team discussions where alternatives for solutions are discussed before decisions are made, and there is also room for individual influence within a team context (for example, CIs no. 8 and 18). However, the alignment between task and method remains, and the examples reveal adherence to routines and pre-designed measurement methods such as complying with requirements and using pre-set screening methods.

\section{Goal-oriented learning}

CIs with goal-oriented learning show performance measurements that are usually decided 'top-down', specifying particular tasks, such as a specific target or goal to achieve. However, the choice of performance measurement method and the responsibility for results are delegated to the staff. One featured example (CI no. 9) describes direct and defined problems, as defined by a pre-determined quota; in this case, the number of faulty telephone directions made by the automatic system. The choice of measurement design and execution and how to handle the results is left to the staff. In CI no. 19, the task is pre-defined but the method and results are conjointly devised within the teams, with high individual and team discretion. Both of these CIs have little alignment among task, method and result.

\section{Creative learning}

In creative learning, the agent has full discretion over the task, method and results. Our featured CI examples (CIs no. 12 and 46) reveal a high degree of integrity and responsibility in the definition of the task, the design of the method, and the handling of results. In CI no. 12, an emergent problem (booking re-visits) triggers the collective choice of a particular task (better planning) and the joint analysis of journals and schedules in order to handle the situation. The result ('prioritisation') is contingencydependent and highly flexible. The same levels of discretion within task, method and 
result is also mirrored in CI no. 46 and assumes a high degree of responsibility for the entire performance measurement process. From an agent perspective, our identified case CIs reflecting creative learning also show a dominance of highly qualified professionals (such as MDs) who can be assumed to have strong professional legitimacy and authority in the organisation, granting liberties but also high levels of responsibility and freedom. The structural context may be assumed to contribute to agent discretion, providing conditions for higher learning readiness and developmental initiatives.

\section{Notes on absence of learning conditions}

Contextual and/or individual factors inhibited or obstructed observable conditions for learning in 20 of the CIs. Descriptive examples of critical incidents where very limited conditions for learning and/or improvement could be found include CI no. 38, in which the sheer numbers of quantitative performance measurements produced within the studied organisation creates an overload of information, which led to lost opportunities for learning. CI no. 54 describes how the visualisation of quantified performance measurements is not enough to create the conditions necessary for any kind of learning and/or improvement. In CI no. 68, MDs describe a particular performance measurement as a nuisance, which irritates staff and discourages any kind of conditions for learning.

\section{Summary of results}

Two-thirds of the CIs containing identifiable learning processes were of an adaptive nature (that is, either reproductive or rule-based) and the remaining one-third were developmental in nature (that is, goal-oriented or creative). Table III shows the distribution of the four different learning facets found in the CIs within the different personnel categories. Our results, as displayed with our featured examples, show that performance measurement is achieved in many different forms and that the nature of the learning is highly reflected in the design, context and execution of performance measurement. We further show that the degrees of freedom induce certain types of learning and vice versa and that agent discretion plays an important role in determining the facet of learning. The continuum from control to improvement is conditioned by three aspects characterising the workplace: task, method and results.

Table III. The distribution of learning facets within CIs amongst studied personnel categories.

\begin{tabular}{lcccc}
\hline & Reproductive & Rule-based & Goal-oriented & Creative \\
\hline MD & 5 & 11 & 4 & 7 \\
$\begin{array}{l}\text { Nurses and other care } \\
\text { personnel }\end{array}$ & 12 & 15 & 4 & 7 \\
$\begin{array}{l}\text { Managers and } \\
\text { administrators }\end{array}$ & 14 & 4 & 8 & 5 \\
$\begin{array}{l}\text { Organisational } \\
\text { developers }\end{array}$ & 2 & 1 & 1 & 3 \\
Total & 33 & 31 & 17 & 22
\end{tabular}


Table III shows that many different groups of professionals are involved in the utilisation of performance measurement. Most of the critical incidents were from the nurses and other care personnel group. Also, the managers and administrator group, as well as medical doctors, were linked to many CI. These three groups were involved in all of the four different learning situations, albeit with a general tendency towards more adaptive processes. It is noteworthy that MDs score relatively high on creative learning.

\section{Discussion}

The present study sheds light on learning processes that occur over a wide range of workplace situations in which performance measurement are being used. In line with this, the purpose of this study was to contribute to a better understanding of the opportunities for learning found in the practice of performance measurement. In utilising established workplace learning theory, we proposed a tentative framework for learning as a driver for performance measurement. Four facets of learning were identified: reproductive, ruleoriented, goal-oriented and creative learning.

Our empirical investigation showed that it is possible to map performance measurement activities according to the learning conditions they create or support. The findings presented herein suggest that research on management benefits from theory development involving theories and concepts from other, related research fields. The workplace learning literature pointed to key issues interconnecting needs for learning and improvement with performance measurement.

While problems with learning from performance measurements may occur, we observed that some kind of learning always takes place, although it may not be as intended or serving stated organisational purposes. As Ellström (2010) pointed out, the processes of learning, change and improvement do not always need to be positively related. If there is a lack of learning skills, unsupportive structures, or if the motivation or learning skills are absent (Bessant and Tsekouras, 2001), learning can lead to unintended learning outcomes. The conscious design of performance measurements could be viewed as a way of overcoming possible problems in the creation of the environment (Gibson, 1950; 1966). Thus, the individual perception of the context as providing a means for learning and also creating motivation for learning forms a powerful tool in successful operations management aiming for continuous improvement.

Discretion or control (Dworkin, 1978; Ellström, 2001; 2011; Karasek, 1979; Weststar, 2009) provides a valuable concept that supports understanding of how certain facets of learning occurs in performance measurement practice. Task understanding (Hackman, 1969), as well as technical and social factors (Karasek, 1979, Weststar, 2009), affect the individual discretion. This influences job control; that is, the degree of freedom and roles for people in (re-) defining and deciding on the task, methods and results within their professional context (Dworkin, 1978). According to Taris et al. (2003), increasing job control has a positive effect on learning. This would indicate that empowering staff members and increasing discretion, with more individual control over tasks, methods and results, would enable more influence over the learning situation, resulting in more productive type II (creative) learning outcomes. On the other hand, lower discretion levels, with performance measurements having predetermined tasks, methods and results, would constrain the possibilities to influence or change the aspects of learning, resulting in more productive type I (reproductive) learning situations.

Within these settings, an important distinction is whether performance measurement is used for control purposes, where the actor degree of freedom is low, or whether performance measurement is used for improvement purposes, in situations with possibilities for actors to make decisions about how to do things and sometimes even 
what to achieve. One example of the former is when the studied healthcare organisation is exposed to performance measurements targeted at compliance with county council regulations (CI no. 11). This is a situation in which the healthcare personnel need to focus on doing the job; that is, following the pre-determined hygiene standards with very low levels of discretion. The latter purpose may be exemplified through the creative job of identifying the causes for a sudden increase in infections (CI no. 46). This situation required a lot of new thinking, team efforts and root cause analysis of the central problems. In this situation, tasks, methods and results were defined by the team that solved the problem - a situation with high discretion. In between these two activities, we find critical incidents that enable some degrees of freedom and some discretion for the parties involved. We illustrate this in the results section using the example of an incident of compliance with time for new visits where the team had freedom in how to investigate this problem and what the solution could be (CI no. 9). However, the task was defined by the standard rules for compliance (in this particular CI, a maximum of 90 days waiting time). So, the continuum of learning can be expressed in terms of whether the task, method and results are determined in advance. That will give the healthcare personnel various opportunities and degrees of freedom in terms of how they solve problems and learn from situations.

In situations of goal-oriented and creative learning, participants are more involved in determining and interacting with the data. In such situations the aim is to make sense of and obtain a feeling for the data. Competence in using performance measurement in those situations is, arguably, very important. Participants need to be able to use existing measures in new ways or develop new measures for the specific task at hand. They also need to be aware of the various ways in which data may be represented and analysed. Thus, goal-oriented and creative learning as a driver for improvement seems to be reliant on active engagement and competence among participants.

We found similarities with Canonico et al. (2015) in that performance measurements used in contexts of control often entail a low interaction with data and primarily reflect management directives. In these situations, measurements are used in a top-down fashion, mainly to instruct participants about what is important, what the gap is and what is needed to close the gap. For instance, the instructions for compliance with pre-surgery hygiene routines are quite clear and there is not so much room for variation in terms of how to carry out this activity. The learning subjects only need to know that they should follow the instructions that are based on evidence from research.

A major difference between performance measurements used for control and for improvement is 'contact' and discretion to utilise data. When the degrees of freedom for various forms of actions increase, performance measurement becomes one's own learning and makes it possible to make sense of the data. In this context, the designer of the performance measurement is also the interpreter of the information. All this creates a robust process for creative knowledge creation. A special case resulting in creative learning occurred when the method was given but the task and results were not. This particular situation was not featured by Ellström (2001) but is exemplified in CI no. 12 (see Table 2) and also found in CIs no. 35, 55, 56, 66, 72 and 73. The task is realised by the individual who utilises available data from earlier performance measurement activities and acts according to his or her own professional discretion in order to achieve desired results.

On the other hand, when the measurement is used for control purposes, the preconditions are sometimes the opposite. Few of the people involved in the control context have been involved in the design and development of knowledge. Our study also indicates that learning facets may interchange, back and forth, within a particular performance 
measurement activity, sometimes even allowing simultaneous learning levels. Therefore, design of performance measurement requires continuous reflection and conscious balancing of learning facets (Ellström, 2011).

Another finding for future studies to explore is the importance of legitimacy. Legitimacy refers to the lawful gain or collective acceptance of power to exercise authority within organisations. Our results suggest that agent discretion and possibilities for creative learning seem to be affected by the organisational legitimacy of the involved actors. A majority of the respondents that describe performance measurement as supportive of creative learning were MDs, team leaders or organisational developers; that is, relatively senior members of organisational groups that typically enjoy superior access structures (March and Olsen, 1976) and professional or positional legitimacy (Dowling and Pfeffer, 1975). This finding raises the question of how organisations can empower broader staff groups, thereby increasing legitimacy and the possibility for a wider range of actors to utilise performance measurement for developmental learning.

Performance measurement design has the potential for greater impact on improvement efforts in operations management. Mapping operations management practices (such as performance measurement) and the different conditions for learning gives practitioners the opportunity to harness and manage inevitable learning participation (Sfard, 1998) and increase the potential for organisational improvement. Understanding workplace learning theory in performance measurement also helps to detect dysfunctional learning environments, offering the possibility to break inhibiting hierarchies of learning and overcoming learning obstacles and constraints.

\section{Limitations}

We used a single case situated in a healthcare context, which arguably contains a positivist and evidence-focused paradigm, governing performance measurement and learning. However, an underlying rationale in the sample choice was its richness and variety in performance measurement methods and practices, which make the case fill illustrative purposes. We have tried to follow the notions of Walker et al. (2015) in a modest effort to make a conceptual advance by incorporating and integrating behavioural science theory in in an operations management perspective. As such, our sampling strategy could be described as "critical case" and "typical case" (Miles and Huberman, 1994) in an effort to support analytical generalisation (Firestone, 1993). The present study can be seen as an evolved theoretical perspective on learning processes in relation to performance measurement and addressing a perceived gap in traditional production and operations management research. However, in order to conceptually validate and pave the way for further analytical generalisation, additional cases will have to be studied (Miles and Huberman, 1994; Firestone, 1993).

\section{Managerial implications}

We argue that all managers must consider what kind of learning environment and what kind of learning outcomes best serve the interests of their organisation. Purposeful and carefully designed organisational arrangements and learning environments are more likely to induce intended learning outcomes. This has a great impact on the design and implementation of necessary performance measurement. Managers who empower employees and entrust them with the capabilities and means that enable them to manage the tasks, methods and results of performance measurement are more likely to drive successful organisational improvement efforts. Balancing adaptive and developmental learning (Ellström, 2010) with exploitation and exploration (March, 1991) is necessary for modern organisations, which must include an analysis of the required facets of 
learning. Therefore, managers on every level need to consider what metrics are integrated into management meetings, professional meetings, workplace meetings, in development programmes and even in daily work. These arenas can be seen as learning resources that can potentially increase opportunities to critically question the prevailing conditions and to find new solutions to problems that arise. The arenas create opportunities to integrate measurements in the workplace activities and, ultimately, facilitate performance measurement as a driver for increasing knowledge in organisations.

\section{References}

Alvesson, M. and Sköldberg, K. (2009), Reflexive methodology: new vistas for qualitative research. (2. ed.), SAGE Publication, Los Angeles, CA.

Antonacopoulou, E. P. (2006), "Working Life Learning: Learning-in-Practise", in Antonacopoulou, E.P., Jarvis, P., Andersen, V., Elkjaer, B. and Høyrup. S. (Eds.), Learning, Working and Living. Mapping the Terrain of Working Life Learning, Palgrave Macmillan, New York, NY, pp. 1-17.

Appuhami, R. (in press), "Exploring the relationship between strategic performance measurement systems and managers' creativity: the mediating role of psychological empowerment and organisational learning", Accounting and Finance, DOI:10.11111/acfi.12287

Aragon, M.I.B., Jiménez, Jiménez D. \& Sanz Valle, R. (2014), “Training and performance: The mediating role of organizational learning”, Business Research Quarterly, Vol.17, pp. 161173.

Aranda, C., Arellano, J. and Davila, A. (2017), "Organizational learning in target setting" Academy of Management Journal, Vol. 60 No 3, pp. 1189-1211.

Argyris, C. and Schön, D. A. (1978), Organizational learning, Addison Wesley, Reading, MA.

Ashton, D.N. (2004), "The Impact of Organizational Structure and Practices on Learning in the Workplace", International Journal of Training and Development, Vol. 8 No.1, pp. 43-53.

Barley, S.R. and Kunda, G. (2001), "Bringing Work Back In", Organization Science, Vol.12 No.1, pp. 76-95.

Behn, R. D. (2003), "Why Measure Performance? Different Purposes Require Different Measures", Public Administrations Review, Vol. 63 No. 5, pp. 586-606.

Bessant, J. and Tsekouras, G. (2001), "Developing Learning Networks", Ai \& Society, Vol. 15 No. 1-2, pp 82-98.

Billet, S. (2001), "Learning Through Work: Workplace Affordances and Individual. Engagement", Journal of Workplace Learning, Vol. 13 No. 5, pp. 209-14.

Bititci, U., Garengo, P., Dörfler, V. and Nudurupati, S. (2012), "Performance measurement: challenges for tomorrow", International Journal of Management Reviews, Vol. 14 No. 3, pp. 305-27.

Bohmer, R.M.J. (2009), Designing Care. Aligning the nature and management of health care, Harvard Business Press, Boston, MA.

Bond, T.C. (1999), "The role of performance measurement in continuous improvement", International Journal of Operations \& Production Management, Vol. 19 No. 12, pp. 131834.

Bourne, M. (2008), "Performance measurement: Learning from the past and projecting the future", Measuring Business Excellence, Vol. 12 No. 4, pp. 67-72.

Bourne, M., Neely, A., Platts, P. and Mills, J. (2002), 'The success and failure of performance measurement initiatives. Perceptions of participating managers", International Journal of Operations \& Production Management, Vol. 22 No. 11, pp. 1288-1310.

Brudan, A. (2010), "Rediscovering performance management: systems, learning and integration", Measuring Business Excellence, Vol. 14 No. 1, pp. 109-23.

Canonico, P., De Nito, E., Esposito, V., Martinez, M., Mercurio, L., and Pezzillo iacono, M. (2015), "The boundaries of a performance management system between learning and control", Measuring Business Excellence, Vol. 19 No. 3, pp. 7-21. 
Chenhall, R.H. (2005), "Integrative strategic performance measurement systems, strategic alignment of manufacturing, learning and strategic outcomes: an exploratory study", Accounting Organizations and Society, Vol.30 No. 5, pp. 395-422.

Coetzer, A. (2007), "Employee perceptions of their workplaces as learning environments", Journal of Workplace Learning, Vol. 19 No. 7, pp. 417-34.

Danermark, B., Ekström, M., Jakobsen, L. and Karlsson, J. Ch. (2002), Explaining Society: Critical realism in the social sciences, Routledge, London.

Dervitsiotis, K. N. (2004), "The Design of Performance Measurement Systems for Management Learning", Total Quality Management, Vol. 15 No. 4, pp. 457-73.

Dossi, A. and Patelli, L. (2010), "You Learn From What You Measure: Financial and Nonfinancial Performance Measures in Multinational Companies", Long Range Planning, Vol. 43 No. 4, pp. 498-526.

Dowling, J. and Pfeffer, J. (1975), "Organizational Legitimacy: Social Values and Organizational Behavior", The Pacific Sociological Review, Vol. 18 No. 1, pp. 122-36.

Dworkin, R. (1978), Taking Rights Seriously, Harvard University Press, Cambridge.

Eisenhardt, K. M. (1989), "Building Theories from Case Study Research", The Academy of Management Review, Vol. 14 No. 4, pp. 532-50.

Elg, M. (2007), "The process of constructing performance measurement", The TQM Magazine, Vol. 19 No. 3, pp. 217-28.

Elg, M., Palmberg Broryd, K. and Kollberg, B. (2013), "Performance measurement to drive improvements in healthcare practice", International Journal of Operations and Production Management, Vol. 33 No. 11/12, pp. 1623-51.

Ellström, P-E. (2001), "Integrating Learning and Work: Problems and Prospects", Human Resource Development Quarterly, Vol. 12 No. 4, pp. 421-35.

Ellström, P-E. (2010), "Organizational Learning”, in Peterson, P., Baker, E. and McGaw, B. (Eds.), International Encyclopedia of Education, Vol. 1, Elsevier, Oxford, pp. 47-52.

Ellström, P-E. (2011), "Informal Learning at Work: Conditions, Processes and Logics", in Malloch, M., Cairns, L., Evans, K., and O'Connor, B. N. (Eds.), The SAGE handbook of Workplace Learning, SAGE Publications, Thousand Oaks, CA, pp. 105-19.

Engeström, Y. (1987), Learning by expanding: An activity-theoretical approach to developmental research, Orienta-Konsultit, Helsinki.

Engeström, Y., and Kerosuo, H. (2007), "From workplace learning to inter-organizational learning and back: the contribution of activity theory", Journal of Workplace Learning, Vol. 19 No. 6, pp. 336-42.

Fang, E.A., Li, X. and Lu, J. (2016), "Effects of organizational learning on process technology and operations performance in mass customizers", International Journal of Production Economics, Vol. 174, pp. 68-75.

Fink, L., Yogev, N. and Even, A. (2017), "Business intelligence and organizational learning: An empirical investigation of value creation processes", Information and Management", Vol. 54 No. 1, pp. 38-56.

Firestone, W. A. (1993), "Alternative arguments for generalizing from data as applied to qualitative research", Educational Researcher, Vol. 22 No. 4, pp. 16-23.

Flanagan, J.C. (1959), "The Critical Incident Technique”, Psychological Bulletin, Vol. 51 No. 4, July, pp 327-58.

Franco-Santos, M., Kennerley, M., Micheli, P., Martinez, V. Mason, S., Marr, B., Gray, D. and Neely, A. (2007), "Towards a definition of a business performance measurement system", International Journal of Operations and Production Management, Vol. 27 No.8, pp. 784801.

Franco-Santos, M., Lucianetti, L. and Bourne, M. (2012), “Contemporary performance measurement systems: A review of their consequences and a framework for research", Management Accounting Research, Vol. 23 No. 2, pp. 79-119.

Fuller, A. and Unwin, L. (2004), "Expansive Learning Environments: Integrating Organizational and Personal Development", in Rainbird, H., Fuller, A. and Munro, A. (Eds.), Workplace Learning in Context, Routledge, London, pp. 126-44.

Gibson, J.J. (1950), The perception of the visual world, Houghton Mifflin Company, Boston. 
Gibson, J.J. (1966), The senses considered as perceptual systems, Houghton Mifflin Company, Boston.

Hackman, J.R. (1969), "Toward understanding the role of tasks in behavioural research", Acta Psychologica, Vol. 31, pp. 97-128.

Hussain, K., Wahab, E., Zeb, A., Khan, M.A., Javaid, M. and Khan, M.A. (2016), "Examining the relationship between learning capabilities and organizational performance: The mediating role of organizational innovativeness", in MATEC Web Conference, MUCET 2017, Vol. 150, pp.1-8, DOI: https://doi.org/10.1051/matecconf/201815006027.

Karasek, R.A. (1979), "Job Demand, Job Decision Latitude, and Mental Strain: Inplications for Job Redesign", Administrative Science Quarterly, Vol. 24 No. 2, pp. 285-308.

Kock, H. (2007), "The team as a learning strategy. Three cases of team-based production in the Swedish manufacturing industry", Journal of Workplace Learning, Vol. 19 No. 8, pp. 480 96.

Kock, H. and Ellström, P. E. (2011), "Formal and integrated strategies for competence development in SMEs", Journal of European Industrial Training, Vol. 35 No. 1, pp. 7188 .

Lebas, M. J. (1995), "Performance measurement and performance management", International Journal of Production Economics, Vol. 41 No. 1-3, pp. 23-35.

Lucas, B. (2015), "Getting the improvement habit", available at: http://qualitysafety.bmj.com/content/25/6/400 (accessed 12 December 2016).

Manuti, A., Pastore, S., Scardigno, A. F., Giancaspro, M. L. and Morciano, D. (2015), "Formal and informal learning in the workplace: a research review", International Journal of Training and Development, Vol. 19 No. 1, pp. 1-17.

March, J. G. (1991), "Exploration and exploitation in organizational learning", Organization Science, Vol. 2 No. 1, pp. 71-87.

March, J. G. and Olsen, J. P. (1976), "Organizational learning and the ambiguity of the past", in March, J. G. and Olsen, J. P. (Eds.), Ambiguity and Choice in Organizations, Universitetsforlage, Oslo, pp. 54-68.

Mausolff, C. (2004), "Learning from feedback in performance measurement systems", Public Performance \& Management Review, Vol. 28 No. 1, pp. 9-29.

Melnyk, S.A., Bititci, U. Platts, K., Tobias, J. and Andersen, B. (2014), "Is performance measurement and management fit for the future?", Management Accounting Research, Vol. 25 No. 2, pp.173-86.

Miles, M.B. and Huberman, A.M. (1994), Qualitative Data Analysis, An expanded Sourcebook, SAGE Publications, Thousand Oaks, CA.

Neely, A. (1999), "The performance measurement revolution: why now and what next?", International Journal of Operations \& Production Management, Vol. 19 No. 2, pp. $205-$ 28.

Neely, A., Gregory, M. and Platts, K. (2005), "Performance measurement system design", International Journal of Operations \& Production Management, Vol. 25 No. 12, pp. 1228 63.

Neely, A., and Al Najjar, M. (2006), "Management learning not management control: the true role of performance measurement?" California Management Review, Vol. 48 No. 3, pp. 10114.

Norros, L. (1995), "An orientation-based approach to expertise" in Hoc, J-M., Cacciabue, P. C. and Hollnagel, E. (Eds.), Expertise and technology: Cognition and human-computer interaction, Erlbaum, Hillsdale, N.J, pp. 141-64.

Nudurupati, S.S., Bititci, U.S., Kumar, V. \& Chan, F.T.S. (2011), "State of the art literature review on performance measurement.", Computers and Industrial Engineering, Vol. 60 No.2, pp. 279-290.

Pidd, M. (2012), Measuring the performance of Public Services. Principles and practice, Cambridge University Press, Cambridge, MA.

Pollitt, C. (2013), "The logics of performance management", Evaluation, Vol. 19 No. 4, pp. 346-63.

Polyani, M. (1967), The Tacit Dimension, Routledge, London. 
Santos-Vijande, M.L., López-Sánchez, J.Á. \& Trespalacios, J.A. (2012), "How organizational learning affects a firm's flexibility, competitive strategy, and performance", Journal of Business Research, Vol. 65 No. 8, pp. 1079-1089.

Serrat, O. (2017), The Perils of Performance Measurement, Asian Development Bank, Washington, DC.

Sfard, A. (1998), "On Two Metaphors for Learning and the Dangers of Choosing Just One", Educational Researcher, Vol. 27 No. 2, pp. 4-13.

Silverman, D. (2004), Qualitative Research: Theory, Method and Practice, SAGE Publications, Thousand Oaks, CA.

Stake, R. (1995), The Art Of Case Study Research, SAGE Publications, Thousand Oaks, CA.

Sun, R. and Henderson, A.C. (2016), "Transformational Leadership and Organizational Processes: Influencing Public Performance", Public Administration Review, Vol. 77 No. 4, pp. 554-565.

Taris, T.W., Kompier, M.A.J., De Lange, A.H., Schaufeli, W.B. and Schreurs, P.J.G. (2003), "Learning new behaviour patterns: A longitudinal test of Karasek's active learning hypothesis among Dutch teachers", Work and Stress, Vol. 17 No. 1, pp. 1-20.

Taylor, A and Taylor, M. (2014), "Factors influencing effective implementation of performance measurement systems in small and medium-sized enterprises and large firms: a perspective from Contingency Theory", International Journal of Production Research, Vol. 52 No. 3, pp. 847-866.

Tidd, J. (1997), "Complexity, Networks and Learning: Integrative Themes for Research on Innovation Management", International Journal of Innovation Management, Vol. 1 No. 1, pp. $1-22$.

Tynjälä, P. (2013), “Toward a 3-P model of workplace learning: a literature review”, Vocations and Learning, Vol. 6 No. 1, pp. 11-36.

Voss, C., Tsikriktsis, N. and Frohlich, M. (2002), "Case research in operations management", International Journal of Operations \& Production Management, Vol. 22 No. 2, pp. 195219.

Walker, H., Chicksand, D., Radnor, Z., and Watson, G. (2015), "Theoretical perspectives in operations management: an analysis of the literature", International Journal of Operations \& Production Management, Vol. 35 No. 8, pp. 1182-206.

Wang, M. (2018), "Learning Goals and Performance Measurement in the Workplace", in Elearning in the workplace, A performance -Oriented Approach Beyond Technology, Springer, Cham, Switzerland, pp. 85-92.

Weststar, J. (2009), "Worker Control and Workplace Learning: Expansion of the Job DemandControl Model", Industrial Realtions, Vol. 48 No. 3, pp. 533-48.

Zhou, W., Hu, H. and Shi, X. (2015), "Does organizational learning lead to higher firm performance? An investigation of Chinese listing companies", The Learning Organization, Vol. 22 No. 5, pp. 271-288.

Zuboff, S. (1988), In the Age of the Smart Machine: The Future of Work and Power, Basic Books, New York, NY. 